\title{
EFFECTIVENESSOF CASEIN PHOSPOPEPTIDE AMORMPHOUS CALCIUM PHOSPHATE WITH OR WITHOUT FLUORIDE ON REMINELIZATION OF ENAMEL CARIES- LIKE LESIONS IN PRIMARY TEETH
}

\author{
Laila M. El Habashy* and Mona Heikal ${ }^{* *}$
}

\begin{abstract}
Objective: To evaluate and compare the remineralization effect of casein phospho-peptide amorphous calcium phosphate with or without fluoride "MI paste" \&"MI Paste Plus" respectively" on the re-mineralization of enamel caries-like lesions in primary teeth.

Material and methods: Artificial caries lesion was made on the labial surface of 40 extracted or exfoliated sound primary teeth which were then divided into 2 halves; one half was treated with one of the tested remineralizing agent "MI paste" or "MI Paste Plus"”' while the other half served as a control. The lesions were evaluated both qualitatively using a polarized light microscope and quantitatively by measuring "calcium and phosphate" content using "energy-dispersive X-ray spectroscopy". Data were collected and analyzed by using paired t-test to compare the control and the study groups for each material, while the "t-test" was used to compare between the two study groups.
\end{abstract}

Results: Both "MI paste" and "MI Paste Plus" showed significant re-mineralization to the subsurface enamel lesions. "MI Paste Plus" showed significantly better results than "MI paste" with an increased amount of calcium " $t=5.59 \mathrm{p}=<0.0001$ ", $\mathrm{Ca} / \mathrm{phosphate}$ ratio " $\mathrm{t}=4.08 \mathrm{p}=0.003$ " and reduction in the amount of phosphate content " $\mathrm{t}=4.57 \mathrm{p}=0.001$ ".

Conclusion: Both "MI paste" and "MI Paste Plus" were effective in enamel remineralization, the addition of fluoride in "MI Paste Plus" acted synergistically with the casein phospho-peptide amorphous calcium phosphate and gave better remineralization effect on enamel.

\section{INTRODUCTION}

Prevention is the cornerstone of modern dentistry; minimal intervention has become the standard of care in today's dental practice ${ }^{(1)}$. Studies had shown that subsurface enamel lesions can be effectively treated by the topical use of fluoride. However, the problem with fluoridated toothpaste is that young children tend to swallow it instead of expectorate

* Assistant Professor of Pediatric Dentistry, Pediatric Dentistry and Oral Public Health Department, Faculty of

Dentistry, Alexandria University, Egypt

** Pediatric Dentist at Health Insurance Organization. 
it, increasing the risks of fluoride toxicity and fluorosis ${ }^{(2)}$. Therefore, there was a strong need for a re-mineralizing agent that is non-toxic, and that can be safely used in young children for the prevention of early childhood caries ${ }^{(3)}$. The Recaldent ${ }^{\mathrm{TM}}$ casein phosphopeptide-amorphous calcium phosphate "CPP-ACP" technology was developed in Australia at the University of Melbourne, to address the anticaries properties of milk ${ }^{(4,5)}$.

Eric Reynolds and his coworkers showed that it was the caseinphospho-peptides "CPP", a particular part of the casein protein that was responsible for the tooth-protective activity ${ }^{(6)}$.CPP has a surprising capacity to "stabilize calcium and phosphate as nanoclusters of ions in solution", forming "CPPACP” (7). MI Paste was released by Recaldent ${ }^{\mathrm{TM}}$ "CPP-ACP" to adhere to plaque pellicle, soft tissue and hydroxyapatite, conveying amorphous calcium and phosphorous into the saliva and plaque fluid. Caries is a demineralization and remineralization process, where the major source of mineral loss is the destruction of hydroxyl apatite crystals producing water as a by-product and releasing calcium hydrogen phosphate from enamel giving a porous enamel surface.

When "MI paste" is placed on the tooth surface it interacts with hydrogen ions forming the same species of calcium hydrogen phosphate. Under a diffusion gradient it enters into the porous enamel, reacting with and consuming the water to reproduce enamel minerals, thereby compensating subsurface mineral $\operatorname{loss}^{(6,7)}$. The efficacy of the "CPP-ACP" technology in preventing demineralization and boosting re-mineralization of enamel in vivo ${ }^{(8,9)}$ and in vitro has been proved in literature. "CPPACP" also showed that its incorporation into glass ionomer cements improved both the micro tensile bond strength and compressive strength of the material, moreover, it enhanced the release of calcium, phosphate and fluoride ions at both neutral and acidic $\mathrm{pH}^{(10,11)}$ resulting in better enamel remineralization $^{(12)}$. High concentrations of the inorganic content in "CPP-ACP" enhanced the enamel re-mineralization on bovine enamel and prevented bovine dentine demineralization as well (13,14). "CPP-ACP" was proved to be potentially effective in controlling caries lesions ${ }^{(15)}$.

Casein phosphopeptides has showed its ability to bind fluoride, stabilizing calcium fluoride phosphate as soluble complexes on the enamel surface ${ }^{(9)}$ which resulted in the development of a new material "MI Paste Plus"TM "CPP-ACPF" containing 900 parts per million "ppm" sodium fluoride " $0.2 \%$ "(6). In a study comparing the re-mineralizing effect of " $\mathrm{CPP}$ $\mathrm{ACP}$ " on artificially demineralized enamel lesions, or when applied in combination with $0.22 \%$ fluoride, it was deduced that combining fluoride with "CPPACP" produced higher enamel re-mineralization ${ }^{(16)}$. In an in vitro study using "Diagnodent and scanning electron microscope", it was found that "CPP-ACPF" produced greater amount of re-mineralization in artificial enamel lesions in permanent teeth than "CPP-ACP" (17). When the effect of "CPP-ACPF" was compared to that of acidulated fluoride gel on the surface roughness and microhardness of partially demineralized enamel, it was found that both "CPPACFP" and acidulated fluoride gel significantly reduced the demineralization of enamel lesion this was demonstrated by a post-treatment increase in microhardness values ${ }^{(18)}$.

Most of the literature review demonstrated was carried on bovine teeth or permanent teeth, and fewer studies were found on primary teeth. As "MI paste" and "MI Paste Plus" can provide an important instrument for managing and preventing caries in youngsters, therefore, this in-vitro study aimed to evaluate and compare the effect of "CPPACP" paste with and without fluoride on the remineralization of enamel caries-like lesions in primary teeth.

The null hypothesis of this study was there would be no significant difference between "CPP-ACP" with or without fluoride in the remineralization of enamel in primary teeth. 


\section{MATERIALS AND METHODS}

This experimental in vitro study was done in the laboratories of the "Department of Oral Biology, Faculty of Dentistry and Department of Geology, Faculty of Science", and the "Department of Pediatric Dentistry and Dental Public Health, Faculty of Dentistry, University of Alexandria". This thesis has received prior approval from the faculty's research ethics committee.

A total of forty freshly extracted or naturally exfoliated primary anterior teeth were selected out of a pool of seventy teeth collected from the outpatient dental clinics of Alexandria University Hospital. A magnifying lens was used to examine all the teeth after being cleaned and soft tissue debris were removed. The teeth chosen were free of any caries, cracks, or developmental defects. The teeth were dried, and small circles of self-adhesive labels $4 \mathrm{~mm}$ in diameter were placed on the center of the labial surface of each tooth. All the surfaces of the 40 teeth were coated with acid-proof nail varnish; then, the self-adhesive label was removed, exposing only a small window of enamel. The window was standardized in all the specimens to produce a uniform surface area of exposed enamel. Teeth were then kept in the demineralizing solution " $2.2 \mathrm{mM}$ calcium chloride, $2.2 \mathrm{mM}$ potassium dihydrogen phosphate, $0.05 \mathrm{M}$ acetic acid and $1 \mathrm{M}$ potassium hydroxide to adjust the $\mathrm{pH}$ to 4.4 "(24) for 72 hours to create subsurface enamel lesions. Subsequently, they were rinsed with deionized water and stored in artificial saliva (25). The specimens were then randomly divided into two groups depending on the re-mineralizing agent used "Recaldent" wis with or without fluoride: "Group I"“MI paste"; "CPP-ACP", and "Group II"“MI Paste Plus"; "CPP-ACPF" "GC America Inc., IL"; All teeth were then sectioned longitudinally into two halves in a "labiolingual direction through the middle of the window". One half was treated with the re-mineralizing agent, while the other half remained untreated "control"“i.e., 40 pairs of teeth specimens". The remineralizing paste was applied according to the manufacturer's instruction using a cotton tip and was left in contact with the tooth surface for three minutes. The specimens were then rinsed with deionized water and stored in artificial saliva. The treatment was done once daily for ten consecutive days (6).

The specimens were then evaluated quantitatively by measuring calcium and phosphorus utilizing "energy-dispersive X-ray spectroscopy" "EDX"“Jeol JSM-5300, U.S.A". Polarized light microscopy "Olympus America Inc, U.S.A” was used for qualitative evaluation of the body of the lesion.

From each group, 10 teeth halves "randomly picked", and their identical controls were examined with the "polarized light microscope". Thin longitudinal ground sections "below $200 \mu \mathrm{m}$ "(26) were prepared and then washed under running water, and passed in ascending grades of alcohol " 50,70 , 90 and 100\%". Xylol was used for clearance. Canada balsam was the mounting medium used to hold the specimen in place between the slipcover and the glass slide. The specimens were examined by the polarized light microscope with 10X magnification, and photomicrographs were then taken to achieve a comparison between the test and control specimens. The "polarized light microscope can show different birefringence". The minerals in enamel refract polarized light in "two different amplitudes and refractive indices connected to two transmission planes "birefringence" in rays". The "positive birefringence" refers to the smaller amplitude ray "slower ray", and the "negative birefringence" refers to the greater amplitude ray "faster ray"(24).

These may be viewed as the dark brown color and bluish-green color, respectively. Normal enamel has been characterized by its "prismless surface layer, a dark continuous ribbon over the surface with striae of Retzius and alternative Hunter-Shreger bands"(Figure 1). 
The "energy-dispersive X-ray spectroscopy" was used to measure the lesion quantitatively; it is a method of microanalysis integrated into a scanning electron microscope. An electron is expelled from an inner shell of an atom, and when an outer shell electron takes the place of the missing electron, energy is released in the form of "X-ray radiation". The X-rays are then analyzed to provide details on the surface's elemental distribution "Calcium and phosphorous" and detect ions with a concentration of 1 wt percent $(27,28,29)$ (Figure 2).

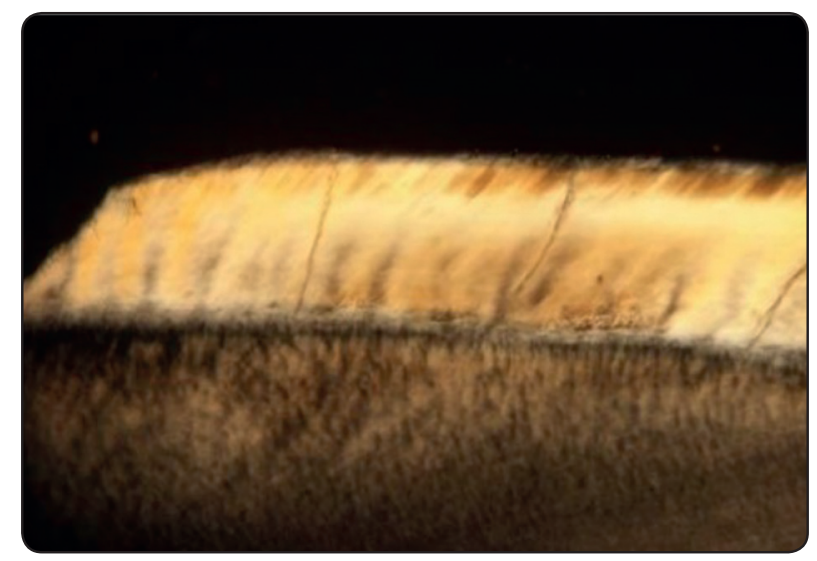

Fig. (1) Polarized light photomicrograph of "longitudinal ground section of normal enamel surface"showing the normal course of the enamel rods reflecting the negative birefringence of the normal calcified enameland alternative bands of brown striae of Retzius.

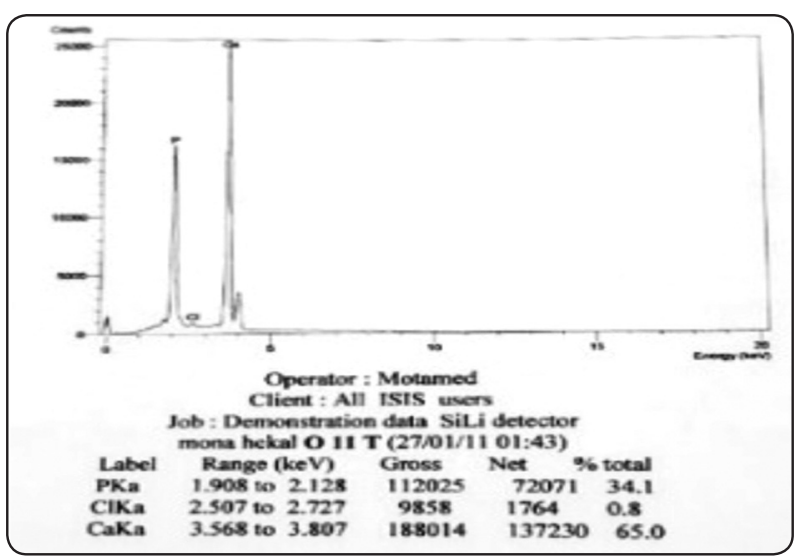

Fig. (2) Elemental analysis of a sample from sub-group 1a after treatment with "CPP-ACP", O stand for the type of group, II is sample number and $\mathrm{T}$ stand for treated. $\mathrm{P}$ Ka means phosphorous at $\mathrm{K}$ level $\mathrm{Ca} \mathrm{Ka}$ means $\mathrm{Ca}$ level at $\mathrm{K}$ level.

\section{Statistical analysis:}

Paired "t-test" was used to compare the "calcium and phosphate" content, also the " $\mathrm{Ca} / \mathrm{P}$ " ratio in the control and the study groups for each material. T-test was used to compare between the two study groups. Normality was checked using the Kolmogorov Smirnov test. Significance was set at the 5\% level. For statistical analysis, SPSS "version 20" was utilized.

\section{RESULTS}

The polarized light microscopy showed that the test specimens in both groups treated with "MI paste"(Figure 3) or "MI Paste Plus"(Figure 4) demonstrated, variable degrees of re-mineralization,

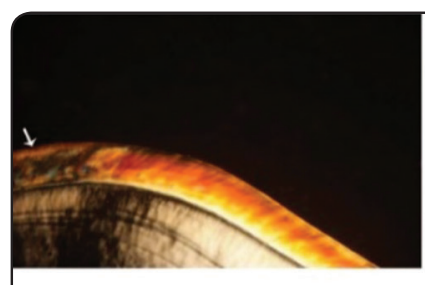

a

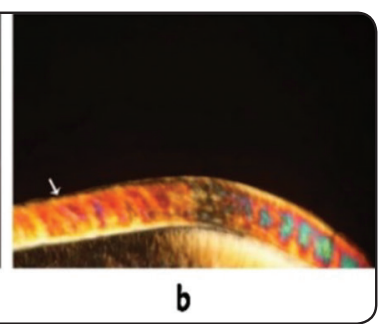

Fig. (3) Polarized light photomicrograph of "longitudinal ground section of enamel" in group (I) MI paste: a) Control specimen showing positively birefringent demineralized enamel with a faint dark band extending to the amelodentinal junction. b) Test specimen showing an evident decrease in the extent of the body of the lesion compared to the control.
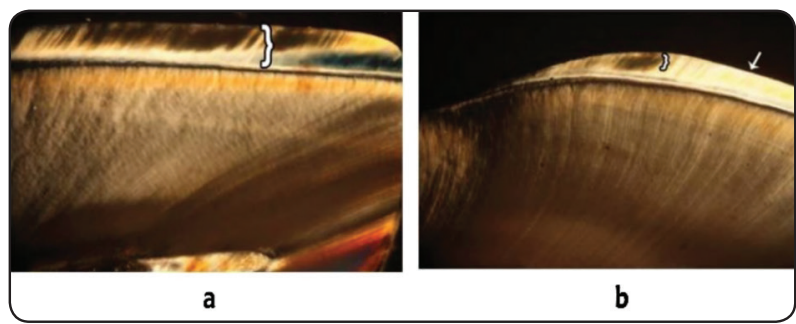

Fig. (4) Polarized light photomicrograph of a "longitudinal ground section of enamel" in group (II) "MI Paste Plus": a) Control specimen showing the extent of the lesion reaching almost to the amelodentinal junction. $b$ ) Test specimen showing the reduction in the depth of the body of the lesion and uniformly negative birefringence surface zone. 
when compared with their control specimens, the body of the lesion in the test groups showed a decreased degree of "positive birefringence" and a "negatively birefringent" surface zone indicating lessened degree of demineralization.

Group II "MI Paste Plus" showed a higher degree of remineralization than Group I "MI paste" demonstrated by a surface zone with uniformly negatively birefringent that composed a considerable proportion of the entire lesion depth (Figure 5).

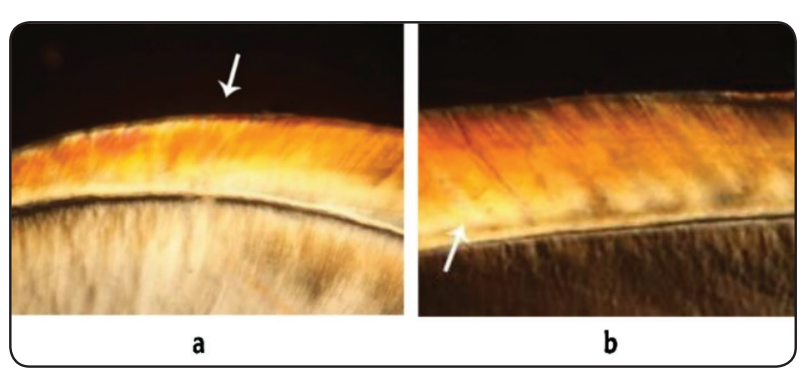

Fig. (5) Polarized light photomicrograph of "longitudinal ground section of enamel test specimens" in both groups: a) Group I MI paste showing a negatively birefringent surface zone. b) Group II "MI Paste Plus" showing a uniform zone of negative birefringence indicating higher remineralization.

The control specimens in both groups revealed the four characteristic zones of the early enamel lesion "subsurface enamel lesion without cavitation". From "deep to superficial, a transparent zone, a dark zone, lesion core, and surface zone with positive birefringence (dark color) and loss of striae of Retzius and Hunter-Shreger bands"(26).(Figure 6)

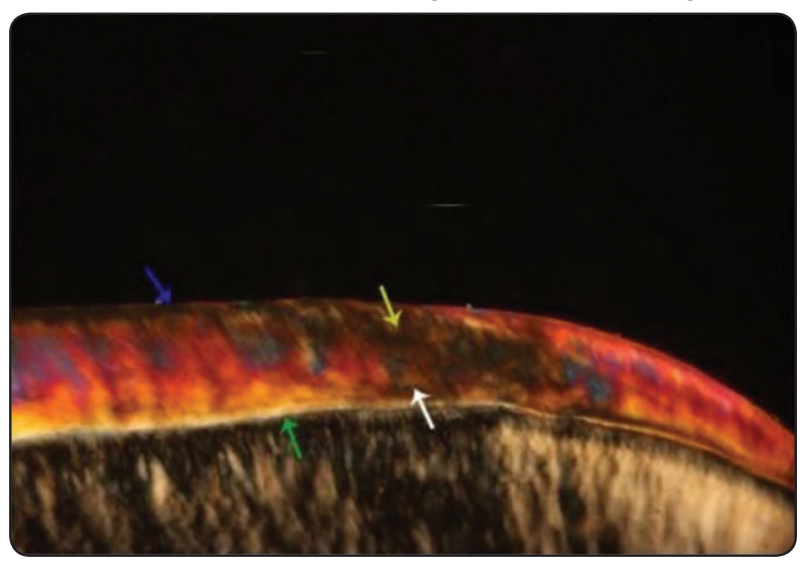

Table 1 shows the EDX spectroscopy results of "MI paste"“Group I": There was a significant increase in the mean calcium content in the test specimens $61.68 \pm 3.95$ than their control $58.34 \pm$ 3.48 " $\mathrm{P}=0.005^{*}$ ". There was a significant decrease in the mean phosphorous content in the test specimens $35.04 \pm 3.74$ than their control $38.80 \pm 3.01$ " $\mathrm{p}=$ 0006 ". The " $\mathrm{Ca} / \mathrm{P}$ " ratio was significantly higher in the test specimens $1.79 \pm 0.29$ than their control $1.52 \pm 0.20$ " $\mathrm{p}=0006$ ”.

Table 2 shows the EDX spectroscopy results of "MI Paste Plus"“Group II": There was a significant increase in the mean calcium content in the test specimens $66.13 \pm 3.12$ than their control 58.92 \pm 4.73, , $\mathrm{P}<0.0001$ ". There was a significant decrease in the mean phosphorous content in test specimens $29.97 \pm 5.74$ than in their control $38.42 \pm 3.71$ " $\mathrm{p}=0.001$ ". The " $\mathrm{Ca} / \mathrm{P}$ " ratio was significantly higher in the test specimens $2.30 \pm 0.52$ than their control 1.56 \pm 0.29 " $\mathrm{p}<0.003$ ”.

A significant difference was found between both test groups "MI paste and "MI Paste Plus" in the mean calcium content, phosphorus content, and calcium/ phosphorus ratio. The "MI Paste Plus" showed a significantly higher mean calcium content $66.13 \pm 3.12$ than MI paste $61.68 \pm 3.95$ " $\mathrm{P}=$ 0.01 ". "MI Paste Plus" showed significantly higher calcium/phosphorus ratio $2.30 \pm 0.52$ than MI paste $1.79 \pm 0.29$ "P=0.04". MI paste showed a higher mean of phosphorous content $35.04 \pm 3.74$ than "MI Paste Plus” $29.97 \pm 5.74$ “P= 0.02”(Table 3).

Fig. (6) Polarized light photomicrograph of a "longitudinal ground section of demineralized enamel" showing a high degree of positive birefringence with loss of the typical striae of Retzius and prism markings within the body of the lesion. The 4 zones of the early enamel lesion can be seen: Green arrow shows the translucent zone most deeply; immediately within it is a second dark zone (white arrow); the yellow arrow shows the body of the lesion and the blue shows of the surface zone. 
TABLE (1) Comparison between remineralized samples and their controls in group I MI paste

\begin{tabular}{|c|c|c|c|c|c|}
\hline \multirow{2}{*}{} & \multicolumn{2}{|c|}{ Mean (SO) } & \multirow{2}{*}{ Difference (CI) } & Paired t test & P value \\
\cline { 2 - 5 } & $\begin{array}{c}\text { Remineralized } \\
\text { samples }\end{array}$ & $\begin{array}{c}\text { Demineralized } \\
\text { samples }\end{array}$ & $\begin{array}{c}3.34 \\
(1.36 .5 .31)\end{array}$ & 3.90 & $0.005^{*}$ \\
\hline Calcium & $61.68(3.95)$ & $58.34(3.48)$ & $\begin{array}{c}3.76 \\
(1.45 .6 .06)\end{array}$ & 3.75 & $0.006^{*}$ \\
\hline $\begin{array}{c}\text { Calcium/ } \\
\text { phosphorus }\end{array}$ & $35.04(3.74)$ & $38.80(3.01)$ & $\begin{array}{c}0.27 \\
(0.10,0.44)\end{array}$ & 3.74 & $0.006^{*}$ \\
\hline
\end{tabular}

*: Statistically significant at $P \leq 0.05, n=10$

TABLE (2) Comparison between remineralized samples and their controls in group II MI paste Plus

\begin{tabular}{|c|c|c|c|c|c|}
\hline & \multicolumn{2}{|c|}{ Mean (SO) } & \multirow[b]{2}{*}{ Difference $(\mathrm{CI})$} & \multirow[b]{2}{*}{ Paired $t$ test } & \multirow[b]{2}{*}{$\mathrm{P}$ value } \\
\hline & $\begin{array}{l}\text { Remineralized } \\
\text { samples }\end{array}$ & $\begin{array}{c}\text { Demineralized } \\
\text { samples }\end{array}$ & & & \\
\hline Calcium & $66.13(3.12)$ & $58.92(4.73)$ & $\begin{array}{c}7.22 \\
(4.30,10.13)\end{array}$ & 5.59 & $<0.0001 *$ \\
\hline Phosphorus & $29.97(5.74)$ & $38.42(3.71)$ & $\begin{array}{c}8.45 \\
(4.27,12.63)\end{array}$ & 4.57 & $0.001 *$ \\
\hline $\begin{array}{l}\text { Calcium/ } \\
\text { phosphorus }\end{array}$ & $2.30(0.52)$ & $1.56(0.29)$ & $\begin{array}{c}0.74 \\
(0.33,1.15)\end{array}$ & 4.08 & $0.003 *$ \\
\hline
\end{tabular}

*: Statistically significant at $P \leq 0.05, n=10$

TABLE (3) Comparison between remineralized samples in both groups: MI paste and MI paste Plus

\begin{tabular}{|c|c|c|c|c|c|}
\hline & \multicolumn{2}{|c|}{ Mean (SD) } & \multirow{2}{*}{ Difference (CI) } & t test & P value \\
\cline { 2 - 5 } & $\begin{array}{c}\text { MI paste } \\
\text { Rcmincralizcd samples }\end{array}$ & $\begin{array}{c}\text { MI paste Plus } \\
\text { Rcmineralizcd samples }\end{array}$ & $\begin{array}{c}4.45 \\
(1.02,7.87)\end{array}$ & 2.74 & $0.01 *$ \\
\hline Calcium & $61.68(3.95)$ & $66.13(3.12)$ & $\begin{array}{c}5.08 \\
(0.33,9.83)\end{array}$ & 2.26 & $0.04 *$ \\
\hline $\begin{array}{c}\text { Phosphorus } \\
\text { phosphorus }\end{array}$ & $35.04(3.74)$ & $29.97(5.74)$ & $\begin{array}{c}0.51 \\
(0.10,0.92)\end{array}$ & 2.60 & $0.02 *$ \\
\hline
\end{tabular}

\footnotetext{
*: Statistically significant at $P \leq 0.05, n=10$
} 


\section{DISCUSSION}

The null hypothesis of the present study was rejected since "CPP-ACPF" showed better remineralization potential than "CPP-ACP" alone.

In this study, we used qualitative and quantitative methods to evaluate remineralization of the artificial caries lesion in order to give more comprehensive details, as most of the studies use either of these methods but in this study, our goal was to relate between the quantitative results of the calcium and phosphate content in enamel and the different histological appearance of enamel surface after demineralization/remineralization process.

The polarized light microscopy results of the present study showed that normal enamel has a negative birefringence, and with the demineralization process, it becomes more porous. These pores become filled with air, which has a different refractive index than that of the enamel, and this is what gives the carious enamel its positive birefringence. The polarized light photomicrographs of the control specimens showed positive birefringence, whereas, the specimens treated with "GC MI paste" and "GC MI Paste Plus", exhibited a shift from the positive to negative birefringence. This means that the pores were filled with calcium, phosphate, or fluoride ions approaching the normal enamel structure, and thus, the negative birefringence occurred. These findings agreed with Kumar et al. ${ }^{(24)}$, who concluded that the "CPP-ACP" decreased the artificially created subsurface lesion depth.

Although both test groups showed signs of remineralization after ten days of treatment with "MI paste or MI paste Plus". Yet, the fluoride-containing paste showed a higher degree of remineralization demonstrated by a dramatic decrease in the extent of the body of the lesion, the surface zone was uniformly negatively birefringent and composed a considerable proportion of the entire lesion depth. The addition of fluoride to the paste "MI Paste Plus", accentuated this shift to an almost normal negative birefringent enamel denoting better remineralization, this was due to the ability of "CPP" to connect fluoride as well as calcium and phosphate, forming calcium fluoride phosphate as soluble complexes. These findings were supported by Salman et al. ${ }^{(30)}$, who reported a higher lesion depth reduction following remineralization by MI varnish containing fluoride. Kumar ${ }^{(24)}$ also postulated the additive anti-cariogenic effect of the conjunctional use of fluoride and "CPP-ACP" increasing the remineralization potential.

Confirming the polarized light microscopy findings of this study, the energy dispersive x-ray spectroscopy resultsalso showed that both groups treated with MI paste and "MI Paste Plus" significantly increased the mean calcium content when compared to their control groups. This finding expanded upon the capability of "CPP" to stabilize nanoclusters of amorphous calcium phosphate, preventing their growth into the critical size for phase transformations ${ }^{(5,16)}$.This guarantees that the ions are bioavailable for diffusion through the lesions deficient in minerals allowing the demineralized crystals to become re-mineralized though prohibiting surface deposition in the shape of calculus ${ }^{(9)}$. Subsequently, there was a significant increase in the $\mathrm{Ca} / \mathrm{P}$ ratio in the test groups than their control, indicating lesion re-mineralization. The current results agreed with those by Hegde and Moany $2012^{(29)}$, who stated that the enhanced enamel re-mineralization is due to the presence of inorganic calcium and phosphorus in high concentrations in the "CPP-ACP".

When the MI paste was compared with the "MI Paste Plus", there was a significant increase in the mean calcium content and calcium/ phosphorus ratio in "MI Paste Plus" than the "MI paste" specimens. The better results obtained with the "MI Paste Plus" can be attributed to the confinement of the amorphous calcium fluoride phosphate "ACFP" at the tooth surface by the casein phosphor-peptides, which would co-localize calcium, phosphate and fluoride ions. This helps to maintain a state of super saturation suppressing demineralization ${ }^{(31,32)}$. The results of the present study were endorsed by those 
of EL Sayad et al. ${ }^{(16)}$ who deduced that "CPP-ACP" paste can re-mineralize subsurface enamel lesion better than artificial saliva and that combining with $0.22 \%$ sodium fluoride, had a synergistic effect on their remineralization potential. This finding

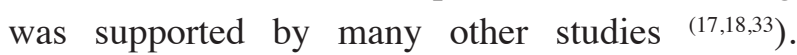
Furthermore, Heshmat et al. ${ }^{(34)}$ reported that "MI Paste Plus" was effective in decreasing the surface roughness of enamel after bleaching Salman et al. (30)found a significant increase in "calcium and phosphate" content in enamel after remineralization with MI varnish containing fluoride. A recent study by Abdelazizet al. ${ }^{(35)}$ was also in accordance with the results of the present study as they concluded that "CPP-ACPF" and nanohydroxyapatite were both equally effective in re-mineralization of early caries-like lesions of young permanent teeth.

However, our result was inconsistent with Huang et al. (36) who concluded that "MI Paste Plus" and PreviDent fluoride varnish" didn't appear to be more effective than normal home care for improving the appearance of white spot lesions over eight weeks. This was also supported by Moniek et al. ${ }^{(37)}$ who stated that the additional use of "MI Paste Plus" in patients with subsurface enamel lesions after orthodontic fixed appliance treatment did not improve these lesions during the year following debonding. Our justification for the different findings between our study and theirs is the different shifts in salivary $\mathrm{pH}$ in patients that depend on various individual variations, most importantly the dietary habits and amount of sucrose ingested that can lower the salivary $\mathrm{pH}$ to a great extent. Accordingly, this would prevent the remineralization process and hindered the effect of "MI Paste Plus", on the other hand in our study the salivary $\mathrm{pH}$ was constant 6.8 which enhanced the action of the remineralizing agents and this would be considered one of the limitations of the in vitro studies that might not accurately mimic what's happening in the oral cavity giving different results than in vivo studies.

\section{CONCLUSIONS}

Based on the limitations of this study, the following can be concluded:

1. "CPP-ACP GC MI paste" and "CPP-ACFP GC MI Paste Plus" are effective in the re-mineralization of enamel caries-like lesions in primary teeth.

2. The incorporation of fluoride to "CPP-ACP" in the form of "CPP-ACFP" gave superior remineralization results than "CPP-ACP" alone.

\section{CONFLICT OF INTEREST}

"The authors declare that they have no conflicts of interest."

\section{ACKNOWLEDGEMENTS}

We would like to acknowledge with much appreciationthe crucial role of Dr Karin Dowidar, "Professor of Pediatric Dentistry, Faculty of Dentistry, Alexandria University" for her continuous support, guidance and motivation that were essential to complete this work.

Our Sincere gratitude to Dr Amal El Hak, "Professor of Oral Biology,Faculty of Dentistry, Alexandria University" for guiding us in the histological part of this work without her knowledge and support this task would have been very hard to accomplish.

\section{REFERENCES}

1. Kidd EAM, Fejerskov O. What Constitutes Dental Caries? Histopathology of Carious Enamel and Dentin Related to the Action of Cariogenic Biofilms. Journal of Dental Research. 2004; 83"suppl 1":C35-8.

2. Cross KJ, Huq NL, O’Brien-Simpson NM, Perich JW, Attard TJ, Reynolds EC. The Role of Multiphosphorylated Peptides in Mineralized Tissue Regeneration. Int J Pept Res Ther. 2007;13:479-95.

3. ten Cate JM. The need for antibacterial approaches to improve caries control. Adv Dent Res. 2009;21:8-12.

4. Schweigert BS, Shaw JH, Zepplin M, Elvehjem CA. Dental caries in the cotton rat; the effect of the amount of 
protein, fat and carbohydrate in the diet on the incidence and extent of carious lesions. J Nutr. 1946;31:439-47.

5. Reynolds EC. Dairy products and dental health. Proceedings of the nutrition society of Australia. 1995;19:95-102.

6. Reynolds EC CF, Shen P, Walker GD. Retention in plaque and remineralization of enamel lesions by various forms of calcium in a mouthrinse or sugar-free chewing gum. J Dent Res. 2003 82:206-11.

7. Cross KJ, Huq NL, Palamara JE, Perich JW, Reynolds EC. Physicochemical characterization of casein phosphopeptide-amorphous calcium phosphate nanocomplexes. J Biol Chem. 2005; 280:15362-9.

8. Llena C, Forner L, Baca P. Anticariogenicity of casein phosphopeptide amorphous calcium phos phate: a review of literature. J Contemp Dent Pract. 2009; 10: 1-9.

9. Reynolds EC. Anticariogenic complexes of amorphous calcium phosphate stabilized by casein phosphopeptides: a review. Spec Care Dentist. 1998 JanFeb;18:8-16.

10. Mazzaoui SA, Burrow MF, Tyas MJ, Dashper SG, Eakins D, Reynolds EC. Incorporation of casein phosphopeptideamorphous calcium phosphate into a glass-ionomer cement. J Dent Res. 2003 Nov;82:914-8.

11. Al Zraikat H, Palamara JE, Messer HH, Burrow MF, Reynolds EC. The incorporation of casein phosphopeptide-amorphous calcium phosphate into a glass ionomer cement. Dent Mater. 2011 Mar;27:235-43.

12. Oshiro M, Yamaguchi K, Takamizawa T, Inage H, Watanabe T, Irokawa A, Ando S, Miyazaki M. Effect of "CPPACP" paste on tooth mineralization: an FESEM study. J Oral Sci. 2007 Jun;49:115-120.

13. Yamaguchi K, Miyazaki M, Takamizawa T, Inage H, Kurokawa $\mathrm{H}$. Ultrasonic determination of the effect of casein phosphopeptide-amorphous calcium phosphate paste on the demineralization of bovine dentin. Caries Res. 2007;41:204-7.

14. Yamaguchi K, Miyazaki M, Takamizawa $\mathrm{T}$, Inage $\mathrm{H}$, Moore BK. Effect of "CPP-ACP" paste on mechanical properties of bovine enamel as determined by an ultrasonic device. J Dent. 2006 Mar;34:230-6.

15. RehderNeto FC, Maeda FA, Turssi CP, Serra MC. Potential agents to control enamel caries-like lesions. J Dent. 2009; 37: 786-90.

16. Elsayad I, Sakr A, Badr Y. Combining casein phosphopeptide-amorphous calcium phosphate with fluoride: syner- gistic remineralization potential of artificially demineralized enamel or not? J Biomed Opt. 2009; 14:044039.

17. Jayarajan J, Janardhanam P, Jayakumar P. Efficacy of "CPP-ACP" and CPPACPF on enamel remineralization an in vitro study using scanning electron microscope and DIAGNOdent. Indian J Dent Res. 2011 Jan-Feb;22:77-82.

18. Mustafa DS. The effect of casein phosphopetide- amorphous calcium phosphate versus fluoride gel on microhardness and surface roughness of partially demineralized enamel: An In-vitro study. [M Sc. Thesis]. Faculty of Dentistry: Ain Shams University; 2011.

19. Zhang Q, Zou J, Yang R, Zhou X. Remineralization effects of casein phosphopeptide-amorphous calcium phosphate creme on artificial early enamel lesions of primary teeth. Int J Paediatr Dent. 2011 Sep;21:374-81.

20. Taleb HS, Rashed M, El-bardissy A, Alshaibah WMB. Comparison of casein phosphopeptide-amorphous calcium phosphate and fluoride gel in remineralization of demineralized human enamel surfaces. Indian Journal of dentistry. 2012; 3:53-7.

21. Mohamed, E., Shoreibah, E., Elmasry, E., Niazy, M., \& Mostafa, M. A Clinical and Laboratory Evaluation of Different Remineralizing Agents Used for Treatment of Carious Posterior Teeth. Al-Azhar Dental Journal for Girls. 2016; 3: 215-22.

22. Bou Chebel, F., Zogheib, C.M., Baba, N.Z., \& Corbani, K. A. Clinical Comparative Evaluation of Nd: YAG Laser and a New Varnish Containing Casein PhosphopeptidesAmorphous Calcium Phosphate for the Treatment of Dentin Hypersensitivity: A Prospective Study. Journal of Prosthodontics, 2018; 27: 860-7.

23. Kijsamanmith, K., Banomyong, D., Burrow, M.F., Kanchanasantikul, P., Wipawiwat, S., Srikam, S., Laojarungphesatchakorn, S. Effect of Conventional and Acidmodified Casein Phosphopeptide-Amorphous Calcium Phosphate Crèmes on Dentin Permeability Before and After Acid Challenge. Oper Dent. 2019 Sep/Oct; 44:530-5. doi: 10.2341/17-382-L

24. Kumar VL, Itthagarun A, King NM. The effect of casein phosphopeptideamorphous calcium phosphate on remineralization of artificial caries-like lesions: an in vitro study. Aust Dent J. 2008 Mar;53:34-40.

25. Kawai K, Heaven TJ, Retief DH. In vitro dentine fluoride uptake from three fluoride-containing composites and their acid resistance. J Dent. 1997 MayJul; 25:291-6. 
26. Nucã C, Stefan Bocskay, Corneliu Amariei, Rusu L-D. Study regarding the histological features of enamel caries. OHDMBSC June, 2005; 4:5-12.

27. Barbour ME, Rees JS. The laboratory assessment of enamel erosion: a review. J Dent. 2004 Nov; 32:591-602.

28. Arnold WH, Dorow A, Langenhorst S, Gintner Z, Banoczy J, Gaengler P. Effect of fluoride toothpastes on enamel demineralization. BMC Oral Health. 2006;6:8.

29. Hegde AM, Moany A. Remineralization of enamel subsurface lesions with casein phosphopeptide - amorphous calcium phosphate: A quantitative energy dispersive X-ray analysis using scanning electron microscopy: An in vitro study. J Conserv Dent. 2012;15:61-7.

30. Salman N, ElTekeya M, Bakry N, Omar S and El Tantawi M. Comparison of remineralization by fluoride varnishes with and without casein phosphopeptide amorphous calcium phosphate in primary teeth, Acta Odontologica Scandinavica, DOI: 10.1080/00016357.2018.1490967

31. Holler BE, Friedl KH, Jung H, Hiller KA, Schmalz G. Fluoride uptake and distribution in enamel and dentin after application of different fluoride solutions. Clin Oral Investig. 2002 Sep;6:137-44

32. Moezizadeh M, Moayedi S. Anticariogenic Effect of Amorphous Calcium Phosphate Stabilized by Casein Phospho- peptid: A Review Article. Res.J.Biol.Sci. 2009;4:132-6.

33. Srinivasan N, Kavitha M, Loganathan SC. Comparison of the remineralization potential of $\mathrm{CPP}-\mathrm{ACP}$ and $\mathrm{CPP}-\mathrm{ACP}$ with 900 ppm fluoride on eroded human enamel: An in situ study. Arch Oral Biol. 2010; 55: 541-4.

34. Heshmat H, Ganjkar MH, Jaberi S, Fard MJ. The effect of remin pro and "MI Paste Plus" on bleached enamel surface roughness. J Dent “Tehran”. 2014; 11:131-6.

35. Abdelaziz R, Mohamed A, Talaat D. Effect of two remineralizing agents on microhardness of initial enamel caries like lesions in young permanent teeth. Alexandria Dental Journal, 2019; 44: 45-9. doi: 10.21608/adjalexu. 2019.63555

36. Huang GJ, Roloff-Chiang B, Mills BE, et al. Effectiveness of "MI Paste Plus" and PreviDent fluoride varnish for treatment of white spot lesions: a randomized controlled trial. Am J Orthod Dentofacial Orthop. 2013;143:31-41. doi:10.1016/j.ajodo.2012.09.007

37. Moniek W Beerens, Jacob M ten Cate, Mark J Buijs, Monique $\mathrm{H}$ van der Veen: Long-term remineralizing effect of "MI Paste Plus" on regression of early caries after orthodontic fixed appliance treatment: a 12-month follow-up randomized controlled trial. Eur J Orthod. 2018 Sep 28;40:457-64. doi: 10.1093/ejo/cjx085 